\title{
ASSESS THE SITUATION IN THE FIELD OF MEDICAL TOURISM SERVICES FROM THE PERSPECTIVE OF EXPERTS ACTIVE IN THIS FIELD (CASE STUDY: ISFAHAN)
}

\author{
Mostafa Nariman \\ Tourism DBA Student Of Bahar Higher Education Institution \\ Mohammad Sharif Beheshti \\ Faculty member of Raghib Isfahani Higher Education Institute
}

\begin{abstract}
Due to the importance resistance economy, or the economy without oil in Iran in recent years and the attention to tourism as a way of engaging, dynamic, profitable and effective in the world's major economies to using all the opportunities in this field and need to move Towardsto this strategy as a stable income, high-value and employment for treatment the growing economy of Iran, accurate identification of strengths, weaknesses, opportunities and threats investment in this field is inevitable In different countries exploit all possible opportunities to attract tourists is done, one of these opportunities, use of local capacity in the health sector in order to attract tourists and this has beenhistorical cease-richas Ancient Egyptian brain surgery to treat various diseases in various countries from China to Iran, the Islamic-Iranian acupuncture medicine is that this self-importance and a new focus to this issue. The methodology this work is descriptive and analytical for health and tourism activities in theIsfahan in 2015 Among them, 158 were randomly selected and collected by questionnaire on their views in relation to security, between road services, nursing care, food, drug and climate quality, accommodation services, transport services, specialized services, advertisements, equipment, cost, and ease visa rules will be discussed with health tourismTo evaluate the hypothesesuse t-test. This study tries to investigate the situation in the field of medical tourism in different dimensions to offer strategies to increase the quality and quantity of income opportunities in this domain. Therefore, by using of Comments of activists in the field of tourism, particularly health tourism in this city the situation we analyzed in terms of strengths, weaknesses, opportunities and threats. Hypotheses indicate that you have in the way of service, accommodations, transportation, promotion and protection laws and facilitate effective activities to accomplish as loopholes so we can get enough of average standards And also considering that in the field of professional services, infrastructure facilities and the cost of the program have an advantage we should provide maintain and improve the situation in these three areas This paper is a result of my research on the Compilation a new model knowledge to organize, attract and guide the medical tourism in Iran.
\end{abstract}

Keywords: health tourism, medical tourism, security, health professional services

\section{INTRODUCTION}

With respect to the use of new methods of knowledge based in attracting and hosting tourists and the importance of special tourism position in resistive economic, its importance in recent decades has been doubled Considering the geographical position of Iran in the region in terms of economic and political as well as having particular potential in tourism development especially health tourism with scientific and more accurate identification of effective factors In medical tourism, including safety, health and transportation services, nursing services, medical and professional services] .... Can provide a model based on the new knowledge-based methods as well as specific to increase foreign exchange earnings from this location. 


\section{THE IMPORTANCE AND NECESSITY OF RESEARCH}

Changing economic position of Iran, based on a twenty-year vision and increase foreign exchange earnings from tourism in the amount of twenty billion dollars a year as a macro-economic objective in this area made us By examining the current situation and identify strengths and weaknesses, opportunities and threats present new solutions in this area, using the models in the world and create a good result towards this goal.

\section{RESEARCH THEORY BASES}

World Tourism Organization's definition of health tourism include: individuals and groups who use climate change with medical purposes, such as mineral water, recovery, treatment etc. to travel there. Of course there are other terms that define and expand the scope of this type of tourism, health tourism, is one of those words, which points to the tourists travel to villages and areas with mineral springs and health hot water. In this type of trip tourist escape from the stresses of everyday life and revitalizing, without medical intervention and monitoring goes on a journey. Usually these tourists do not have a specific physical illness and are looking to benefit from nature healing in other areas. Medical tourism is another word that means tourist travel to use natural therapeutic of tourism resources (mineral water, salt, mud, etc.) that takes place to treat certain diseases or recovery under the supervision and medical intervention. Medical tourism is another form of health tourism that aims to treat physical illness or a surgery under the supervision of doctors in hospitals and therapeutic centers. In this type of tourist health, after treatment the patient may require spaces and tourism services (like hot water) in which his travel tourism will be completed by traveling to areas with these facilities (KhosrowAbadi, Ghasem. 2012). Elsewhere in the definition of medical tourism argue that medical tourism is the tourism of the residence to the place where medical treatment or surgery performed or to be performed, provided that patient at least should stay one overnight in the place. Medical tourism is utilization from combining aspects of tourism with medical services that has become an important business. The major reasons that cause people to receive health care in their choice of international travel, including long waiting lists in developed countries, low cost medical treatment in developing countries, the cost-effectiveness of transport costs international traffic, development of the Internet and the emergence of international communications companies as intermediaries between international patients and hospital networks. Medical facilities: supplies, equipment and medical devices in general are called medical equipment includes any product, equipment, tools, materials, equipment, implants, materials, reagents, laboratory calibrators and software that are provided by manufacturer for man (alone or in combination with other related items) in order to access one of the following objectives: diagnosis, monitoring, prevention, treatment or alleviation of the disease or support the continuation of the process of life. Birth control and sterilization process creation (or disinfection and cleaning) equipment or environment favorable for medical treatment, health care .providing the information for medical purposes using laboratory methods on taken human samples. Diagnosis, monitoring, treatment, relief, compensation, or to postpone injury or disability. Research, investigation, replacement or modification of the anatomy or a physiological process. Advertising: In recent decades, touted as one of the most important tools for success has been suggested in the life of human societies, this tool should be studied carefully as a branch of scientific, social, cultural and scientific communication and with scientific, artistic and expertise look in various aspects of economic, political and cultural use to follow succeed and achieve the objectives of the activities) Dasul 2002) The original vision of promotional activities in the tourism industry is that this type of advertising is not expensive, but an investment to further organizational goals and national foundations And in case of proper implementation of the principles can have valuable achievements in different aspects of the tourism industry. In this regard, the purpose and function of advertising, increase the "marketing and market synergies" and any neglect and lack of proper utilization of these tools, not only caused the failure, but follow the backwardness of competition and overtaking tourism marketing and the failure and bankruptcy in the correct marketing world in the field of international) Ebrahim et al., 2010). Visa: Foreign nationals if they wish to visit monuments and tourist attractions or meeting friends or relatives and enter to the 
another country must obtain a visa from the consular representatives of destination in outside that In this regard, laws, ease of download, the time and cost of obtaining a visa is different.

\section{THEORY AND LITERATURE}

Misbah and colleagues in their article as a model for designing logical data structure, of medical tourism information systems, as a tool for development of medical tourism states that medical tourism occurs when Individual decides to seek treatment travel across international borders. Patients who used to travel to developed countries in recent years are changing their directions toward developing countries. Commercialize medical tourism is heart of its development. In the meantime, the use of systems based on internet as a mechanism that gives customer information and has the ability to meet all his needs, including the introduction of services and access to them that has contributed to the development of medical tourism. In recent years can be seen that in addition to private organizations, governments systematically trying to attract medical tourists. In this article, we briefly review the performance of medical tourism internal and external web-based systems and evaluate the risks of medical tourism, present scenarios for medical tourism workflowin our country with a holistic and interactive approach between the different organizations and a rational structurebased this scenario relying on SSADM to design an information system of medical tourism.Mostafavi et al in their article as ethics in health tourism, expressed health tourism today is an important and growing phenomenon in the world. Iran since past has been a center of health tourism in the region. At the same time, concerns about the ethical aspects of health tourism in the world were existed. The article refers to the ethical issues raised on this issue, discussed moral status in the fields of medical tourism in Iran, including organ transplantation, therapeutic abortion and assisted reproductive technologies. To collect the data, databases, scientific and university system, the rules of parliament, newspaper articles and, Iranmedex, Magiran online news and web pages related to medical tourism in Iran were investigated. Our findings show that there are some possibilities and regulations in cases where increased willingness of citizens to travel to Iran and other countries, and receive health services, but codified ethics guidelines is not available hence proposed such guidelines to be complied. Saraei and colleagues in their paper titled Assessment of tourism in the city of Shiraz, toward sustainable development using SWOT suggests by starting industrial revolution and urbanization, incentive travel and entertainment to meet the needs of the human spirit became necessary, This important created a global phenomenon in recent decades, the term is called tourism industry. Arrivals of tourists in one place can leave economic, social and cultural effects on the environment and would cause the development of the region. This article examines the situation in Shiraz as one of the largest and richest cultural and historical centers in order to feasibility of tourism development for prosperity and sustainable development in all aspects of the region and the country. This study evaluated analysis of strengths, weaknesses, opportunities and threats in advance and weighting factors for SWOT and use appropriate strategy in tourism and strategies for development of tourism in Shiraz is presented. Results of this study suggest that the city of Shiraz due to position and outstanding works of historical, cultural, artistic and literary is located in an aggressive competitive position and has capability to become one of the largest tourist center on international level. And strategies for planning in this study could be useful and effective in Shiraz tourism development. Morovvatisharifabadi and colleagues in their article presented as a model for health tourism development with an integrated approach TOPSIS fuzzy interpretive structural modeling in Yazd province, says that among the various fields of tourism, health tourism because of the capability and competitive advantages is gaining attention. The aim of this study is to provide a comprehensive framework to identify and evaluate the direct and indirect effects of each of the factors influencing the development of health tourism industry in Yazd. Methods In this study, after reviewing the record and to identify factors affecting the development of health tourism, the most important factors were determined using fuzzy TOPSIS technique and in continue were categorized using interpretive structural modeling levels The results show that the update information hospital staff and relevant expertise of doctors with their tasks are the most important factors in the development of health tourism, and should primarily be focused on them. Using the findings of this research can be concluded that the health tourism and its development in Yazd 
province requires serious determination to satisfy patients for examination or treatment referred to Yazd. This important will be possible through investment in equipment and updating hospitals and hospital staff skills development. Morteza Izadi et al in their article as health tourism situation in Iran, opportunity or threat suggests that health tourism, covers any travel for health promotion and as one of the dimensions of tourism, helps sustainable development and dynamic economy. Also health tourism, a national strategy to increase revenue and an arm of national security. This study was performed with aim to evaluate the health tourism and the specific potentials of Iran.Sedaghati et al in their paper as tourism development strategic planning a way for economic development in citiesNishapur as case study states that each region Due to the potential and the existing facilities can be used in different ways in driven development and with the development of a sector also provide the development of other sectors. The first step is to develop the region is economic development. Due to main purpose of tourism that generate revenue and attract investment to the region, and a key and strategic role of tourism in the development of regional tourism is shown. In this paper, with an emphasis on tourist attractions of the city of Nishapur, efforts have been made through the planning strategies for tourism development in the region to the SWOT matrix and using the techniques of tourism development, economic development in Nishapur also be provided. The main findings of the research show that the definition of an interconnected network of tourist attractions of the city and strengthen this network node, sometimes, can be very effective strategies to meet the economic value of the project. . So in order to the objective of such strategies in Nishapur and the emphasis on looking at the city in the city of Nishapur, the definition of first degree base station and three second degree base stations as well as several substations in each of the base stations, trying to create a network of interconnected and interacting and coordinating tourism in the city. Drawing this network in the city, have shown that this network has covered almost the entire area of the city well.

\section{METHODS}

The study is applied research and is as quantitative and qualitative. The required data via attribution survey has been collected. The statistical society activists in the field of tourism - health in Isfahan in 1394 have been operating there and at tourist sites, recreational, security, services, health and welfare were served. Taking into account the population, the sample size was estimated to be 158Sampling of the population concerned, non-probability sampling (available), which is used to evaluate samples from the Cochran method and for analyzing the data, the average sample student $t$ test has been exploited.To assess the reliability of the items, there are different methods. One of the most common and simplest methods to assess reliability, the Cronbach alpha coefficient. This method is known as one of the factors of reliability and dependability. Due to the alpha coefficient .0 .945 show that (Table 1), the internal consistency of items is high.Also validity in terms of faculty of Social Sciences Institute of Higher Education of RaghibIsfahani and the Institute of Higher Education of Bahar, they opinion results show.

Table 1

\begin{tabular}{|c|c|}
\hline \multicolumn{2}{|c|}{} \\
\hline Cronbach's alpha coefficients & The number of each item \\
\hline .954 & 58 \\
\hline
\end{tabular}

In this context, to review the current status of risk factors in medical tourism we used a questionnaire with Likert 5-utilized and we've divided areas of research into eleven general area as the table 2.

\begin{tabular}{|c|}
\hline security \\
\hline Services between the way \\
\hline Ease visa receiving \\
\hline Quality food, medicine, water and air \\
\hline Lodging services \\
\hline
\end{tabular}




\begin{tabular}{|c|}
\hline Transportation service \\
\hline Tourism ads \\
\hline Specialty-Medical Services \\
\hline The cost of health tourism \\
\hline Infrastructure facilities and medical equipment \\
\hline Support and facilitation rules \\
\hline
\end{tabular}

\section{RESEARCH HYPOTHESIS}

\section{The first hypothesis}

H0: Health tourism security in various aspects in Iran is not in good condition (intermediate) $\mathrm{H} 1$ :Healthtourism security in various aspectsin Iran is in good condition (intermediate)

\section{The second hypothesis}

H0: Services between the way in various aspects in Iran is not in good condition (intermediate) H1: Services between the way in various aspectsin Iran is in good condition (intermediate) the third hypothesis

H0: Ease visa receiving in various aspects in Iran is not in good condition (intermediate) $\mathrm{H} 1$ :Ease visa receiving in various aspectsin Iran is in good condition (intermediate)

\section{The fourth hypothesis}

H0: Quality food, medicine, water and air invarious aspectsin Iran is not in good condition (intermediate)

H1: Quality food, medicine, water and air in various aspectsin Iran is in good condition (intermediate)

\section{The fifth hypothesis}

H0; Lodging services in various aspects in Iran is not in good condition (intermediate)

H1: Lodging services in various aspects in Iran is in good condition (intermediate)

\section{The sixth hypothesis}

$\mathrm{H} 0$; Infrastructure facilities and medical equipment in various aspects in Iran is not in good condition (intermediate)

H1: Infrastructure facilities and medical equipmentin various aspectsin Iran is in good condition (intermediate)

\section{The seventh hypothesis}

H0; Tourism ads in various aspects in Iran is not in good condition (intermediate) H1: Tourism ads in various aspectsin Iran is in good condition (intermediate)

\section{The eighth hypothesis}

H0; Specialty-Medical Services in various aspects in Iran is not in good condition (intermediate) H1: Specialty-Medical Services in various aspectsin Iran is in good condition (intermediate)

\section{The ninth hypothesis}

$\mathrm{H} 0$; The cost of health tourism in various aspects in Iran is not in good condition (intermediate) H1: The cost of health tourism in various aspectsin Iran is in good condition (intermediate) The tenth hypothesis

H0; Infrastructure facilities and medical equipment in various aspects in Iran is not in good condition (intermediate)

H1: Infrastructure facilities and medical equipmentin various aspectsin Iran is in good condition (intermediate) 


\section{The eleventh hypothesis}

H0: Rules for investment support in the field of medical and health tourism to attract tourism to travel to Iran in various aspects in the world, is not in good condition(intermediate) $\mathrm{H} 1$ :Rulesforinvestmentsupportin the field of medical and health tourism to attract tourism to travel to Iran in various aspects in the world, is in good condition(intermediate)

\section{THE TEST METHOD THE HYPOTHESIS}

to assess the situation in the area in health tourism by receiving 158 questionnaireswith 54 questions in 11 differentareaswe started to collect and then entered the information in the software espss 22 andweanalyzed student $t$ test to assess the validity of the assumptions results.

\section{FINDINGS}

After student $t$ test on different areas of the assumptions results were as follows.

\section{The results of the hypothesis}

According to the test, $\mathrm{t}$ - test the following conclusions based on the data given in Table 3 and 4 were obtained

\section{The first hypothesis}

Given that the level of error for this test is considered a 5\% and significance level is considered 0.987 and given that this amount is more than significance level of 5\% Therefore the $\mathrm{H} 0$ is not rejected and this difference is not significant, We cannot comment on the security of health tourism.

\section{The second hypothesis}

Given that the error level is considered 5\% for this test and significance level is 0.000 , this is smaller than significance level of 5\% so difference from the average is negative (-0.36709) and based on that assumption $\mathrm{H} 0$ is confirmed. Therefore, we can say that the service sector of tourism between the way the situation is not in good condition.

\section{The third hypothesis}

Given that the level of error for this test is considered a 5\% and significance level is considered 0.064 and given that this amount is more than a significance level of 5\% Therefore this $\mathrm{H} 0$ is not rejected and considering that this difference was not significant, so we cannot comment on the security of health tourism.

\section{The fourth hypothesis}

Given that the level of error for this test is considered $5 \%$ and significance level is considered 0.380 and this amount is more than the 5\% significance level, $\mathrm{H} 0$ is not rejected and considering that this is not a significant difference wecannot comment about the quality of food, medicine, water, air andhealth tourism.

\section{The fifth hypothesis}

Given that the level of error for this test is considered 5\% and significance level is 0.016 and given that this amount is smaller than significance level of 5\% difference and difference from average is negative $(-0.16772)$ so the assumption $\mathrm{H} 0$ is confirmed and we can say tourist accommodation services sector is not in good condition.

\section{The sixth hypothesis}

Given that the error level considered for this test is $5 \%$ and according to the significance level is 0.000 and this value is smaller than significance level of $5 \%$ and difference from the average is negative $(-0.34557)$ so the assumption $\mathrm{H} 0$ is confirmed. Therefore, we can say that the transport services of the tourism do not have good condition in Iran.

\section{The seventh hypothesis}


Given that the error level considered for this test is $5 \%$ and according to the significance level is 0.000 and this value is smaller than significance level of $5 \%$ and difference from the average is negative $(-0.46097)$ thus, $\mathrm{H} 0$ is confirmed. Therefore we can say that the field of advertising to attract tourists does not have good condition.

\section{The eighth hypothesis}

Given that the error level considered for this test is $5 \%$ and according to the significance level is 0.000 and this value is smaller than significance level of $5 \%$ and the difference from average is positive (0.43671). The hypothesis $\mathrm{H} 0$ is rejected therefore, it can be said $\mathrm{H} 1$ is accepted and expertmedical services to attract health tourism is in good condition.

\section{The ninth hypothesis}

Given that the level of error for this test is considered 5\% and significance level is 0.019 and value is smaller than significance level of $5 \%$ and mean difference is positive (.2000) thus the assumption $\mathrm{H} 0$ is rejected and H1 is accepted. Therefore, we can say that the cost of attract tourists health is in good condition.

\section{The tenth hypothesis}

Given that the level of error for this test is considered 5\% and significance level is 0.044 and value is smaller than value of significance level of $5 \%$ and the difference from the average is positive (0.20253) thus the assumption H0 is rejected and H1 is accepted. Therefore, we can say that the infrastructure facilities and medical equipment to attract tourists' health is in good condition.

\section{The eleventh hypothesis}

Given that the error considered for this test is 5\% andsignificance level is 0.000 . and the value is smaller of significance level of $5 \%$, difference from the average is negative $(-0.2859)$ Therefore, H0 is confirmedand thus, we can say rules for investment support in the field of medical and health tourism to attract tourists is in good condition.

T-Test

One test sample

\begin{tabular}{|c|c|c|c|c|c|c|}
\hline & \multicolumn{6}{|c|}{ Test Value $=3$} \\
\hline & \multirow[b]{2}{*}{$\mathrm{t}$} & \multirow{2}{*}{ df } & \multirow{2}{*}{$\begin{array}{l}\text { Signi } \\
\text { fican } \\
\text { ce } \\
\text { level }\end{array}$} & \multirow{2}{*}{$\begin{array}{l}\text { Differ } \\
\text { ence } \\
\text { from } \\
\text { averag } \\
\text { e }\end{array}$} & \multicolumn{2}{|c|}{$\begin{array}{l}\text { confidence interval of the } \\
\text { difference in level } 95 \%\end{array}$} \\
\hline & & & & & lower & higher \\
\hline security & -.016 & 157 & .987 & $\begin{array}{c}- \\
.00105\end{array}$ & -.1275 & .1254 \\
\hline Services between the way & $\begin{array}{c}- \\
5.16 \\
3\end{array}$ & 157 & .000 & .36709 & -.5075 & -.2267 \\
\hline Ease visa receiving & $\begin{array}{c}- \\
1.86 \\
6\end{array}$ & 157 & .064 & $\begin{array}{c}- \\
.11392\end{array}$ & -.2345 & .0067 \\
\hline $\begin{array}{l}\text { Quality of food, medicine, water } \\
\text { and air }\end{array}$ & .880 & 157 & .380 & .05696 & -.0708 & .1847 \\
\hline Lodging services & $\begin{array}{c}- \\
2.44 \\
0\end{array}$ & 157 & .016 & .16772 & -.3035 & -.0320 \\
\hline Transportation service & - & 157 & .000 & - & -.4993 & -.1919 \\
\hline
\end{tabular}




\begin{tabular}{|c|c|c|c|c|c|c|}
\hline & $\begin{array}{c}4.44 \\
1\end{array}$ & & & .34557 & & \\
\hline Tourism ad & $\begin{array}{c}- \\
6.84 \\
1\end{array}$ & 157 & .000 & .46097 & -.5941 & -.3279 \\
\hline Specialty-Medical Services & $\begin{array}{c}5.44 \\
8\end{array}$ & 157 & .000 & .43671 & .2784 & .5950 \\
\hline The cost of health tourism & $\begin{array}{c}2.36 \\
7\end{array}$ & 157 & .019 & .20000 & .0331 & .3669 \\
\hline $\begin{array}{c}\text { Care and medical facilities and } \\
\text { equipment }\end{array}$ & $\begin{array}{c}2.02 \\
9 \\
\end{array}$ & 157 & .044 & .20253 & .0054 & .3997 \\
\hline Support and facilitation rules & $\begin{array}{c}4.52 \\
3\end{array}$ & 157 & .000 & .28059 & -.4031 & -.1581 \\
\hline
\end{tabular}

Table 3

\begin{tabular}{|c|c|c|c|c|}
\hline \multicolumn{5}{|c|}{ One example of Statistics } \\
\hline & $\begin{array}{c}\text { Number } \\
\text { of } \\
\text { samples }\end{array}$ & mean & $\begin{array}{c}\text { Standard } \\
\text { deviation }\end{array}$ & $\begin{array}{c}\text { The standard error of } \\
\text { the mean }\end{array}$ \\
\hline security & 158 & 2.9989 & .80482 & .06403 \\
\hline Services between the way & 158 & 2.6329 & .89363 & .07109 \\
\hline Ease visa receiving & 158 & 2.8861 & .76737 & .06105 \\
\hline $\begin{array}{c}\text { Quality of food, medicine, } \\
\text { water and air }\end{array}$ & 158 & 3.0570 & .81319 & .06469 \\
\hline Lodging services & 158 & 2.8323 & .86393 & .06873 \\
\hline Transportation service & 158 & 2.6544 & .97814 & .07782 \\
\hline Tourism ad & 158 & 2.5390 & .84695 & .06738 \\
\hline $\begin{array}{c}\text { Specialty-Medical } \\
\text { Services }\end{array}$ & 158 & 3.4367 & 1.00765 & .08016 \\
\hline The cost of health tourism & 158 & 3.2000 & 1.06215 & .08450 \\
\hline $\begin{array}{c}\text { Care and medical } \\
\text { facilities and equipment }\end{array}$ & 158 & 3.2025 & 1.25466 & .09982 \\
\hline $\begin{array}{c}\text { Support and facilitation } \\
\text { rules }\end{array}$ & 158 & 2.7194 & .77972 & .06203 \\
\hline
\end{tabular}

\section{LIMITATIONS OF THE STUDY}

Given that data of this research has been prepared through the questionnaire, in addition tothe limitations ofthis kind of research, following limitations has effectsonresearch.

\section{LIMITATIONS UNDER CONTROL}

Since the data in this study in terms of place, is belonging to the geographical area of Esfahan city, perhaps in other cities of the country different results be accomplished and due to the special status of border provinces in attracting and guiding tourism investigatingthis field in these provinces can have effective role to promote medical tourism.Border cities such as Ardabil has great potential for health tourism includes three parts medical tourism, curative tourism, wellness tourism and need review and field studies to assess the situation in his geographical area.

\section{OUT OF CONTROL LIMITATIONS}

Limited knowledge of respondents on matters related to research variables. 
The accuracy of answers provided by respondents.

The length of the questionnaire can cause reluctance of respondents to respond.

\section{RESEARCH SUGGESTION}

\section{According to the results of hypothesis testing it is recommended:}

1. Further study about the status of tourist's security in different aspects of health (physical security, health security, psychological security, social security, etc.) To improve these areas, effective works can be done as well as special attention to the intangible quarantine and intangible security in patient acceptance and effective model in this respect could be responsible for security in the field of health.

2.Given that between the way services for tourists health is in inappropriate condition and it is recommended compared to define international standards and to the world in stablishing between way centers (which offer services for medical tourism) provide effective action in order to increase utility services in this area And with regard to the status of the border region it can be said, create medical unit with proper facilities to accept and treat medical tourists border countries can be considered as a inviolable priority.

3. Given that the results of this research in terms of ease visa receiving show that no comment is done for the desirability of the area, it is suggested with offering a model with a transparent, stable and new visa for international customers Medical services of Iran this situation is improved and determined.

4. In terms of the provision of services in the field of food, drug and climate of quality in terms of respondents has uncertainty for comment and is recommended by providing a new model with the international standards in these areas conditions are improve and determined.

5. In terms of residential services our country is in poor condition, thus providing standard as well as new initiatives for the improvement and development of accommodation in Iran would be effective in this area to increase desirability

6. given that in terms of transport services we are having a negative situation and that shows the bad situation in the field of aviation, marine, rail and ground and it is recommended that in addition to using fleet of the world in this field, we take an action to mobilize and standardization of transport to provide efficient customer service of medical tourism.

7. The lack of effective modulus foradvertising led to low compliance in the field of medical tourists increasing, so offering new, attractive and standardizedmodel in this section that make the difference and creates an important role in order to increase the income of the currency of this section.

8. Due to the desirable specialized medical services in Iran, maintain and improve quo by creating a short-term educational institutions (see the specialized services and tourism) and presenting international training and up to date of the world in the field of specialized medical services for health tourism.

9. Due to the favorable situation in the costs of medical tourism in Iran Maintain the exchange rate at the macro level as well as efficient use of the factors affecting the cost at micro level can be attributed to the preservation and improvement of the aforementioned condition.

10.Given that the quantity and quality of medical services and hospital facilities are in good condition it can be said that the use of new technologies such as nuclear-medicine, IT, for diagnosis and treatment and recovery process and refresh this equipment can maintain and enhance favorable conditions for the area to compete with international and local rivals 
11. As the result of the eleventh hypothesis shows that is it can be said re-examine, modify and create support and facilitate rules in the field of medical tourism can play a role to increase investment in this sector in order to increase foreign exchange income.

\section{REFERENCES}

Azami, Amir, Khajeian, Datis, Tavallaei, Ruhollah and Khastar, Hamzeh. (2008). Bi-monthly human development .71- poly, the fifth Issue 18, Pages 90.

Aghassi, Abdullah EbrahimZadeh, Isa and Hadiani, Zohre. (2009). Security role in the development of sustainable tourism, case study: the city Chabha the first national conference on security and sustainable development of tourism, Isfahan, pp 116

Zulkadir, Ali, Karimi, Abolfazl (2012), the effect of the charge on the sense of safety of tourists Province

Jabari, Alireza, Ferdowsi, Massoud, Keyvan Ara, Mahmoud, Aqarahimi, Zahra (2012), Health Information Management, ninth period, the number of sixth in 1391 Page 1

Zarrabi, Asghar and Zangene, Mehdi (2010). Social security role in the development of sustainable tourism, with an emphasis on Iran- Regional Conference on Tourism, Islamic Azad University of Khomeini Shahr

Asli,Tasci and YasinBoylu, (2009), Cultural Comparison of Tourists' SafeTyperception in Relatin to Trip Satisfaction, School of Tourism and HospitalityManagement, Mugla university, Turkey. Banarsidaschandiwala institute of Hotel Management \& catering Technology,.2009.

Nunkoo, R. and Ramkissoon, H. (2011). Small island urban tourism: a resident's Perspective, Current Issues on Tourism, (3): 37-60.23.

Vornanen, R., Torronen, M. And Ni etalemela, P. (2009). Insecurity of youngPeople: the meaning of insecurity as defined by 13-17- year - old Finns, Young, 17 (4): 399- 419. 